\title{
МНЕНИЕ РОССИЯН ПО ПОВОДУ ПАНДЕМИИ КОРОНАВИРУСНОЙ ИНФЕКЦИИ: АСПЕКТ ТРАДИЦИОННОГО ОБЩЕНИЯ (НА МАТЕРИАЛАХ КОНКРЕТНОГО СОЦИОЛОГИЧЕСКОГО ИССЛЕДОВАНИЯ)
}

\section{Ушакова Алина Павловна}

студент

Научный руководитель: Русанова А.А., к.п.н., доцент, зав. кафедрой социологии ЗабГУ Забайкальский государственный университет

Аннотация. В статье раскрывается специфика социальной коммуникации в период пандемии. Особое внимание автор уделяет традиционному (личному) общению, его актуальности во время ограничения межличностных контактов. В качестве эмпирической базы использованы материалы Инициативного всероссийского опроса «ВЦИОМ-Спутник» от 28 января 2021.

Ключевые слова: социальное взаимодействие, каналы коммуникации, традиционное (личное) общение.

Abstract. The article reveals the specifics of social communication during the pandemic. The author pays special attention to traditional (personal) communication, its relevance during the restriction of interpersonal contacts. The materials of the Initiative All-Russian survey "VTsIOM-Sputnik" dated January 28, 2021 were used as an empirical base.

Key words: social interaction, communication channels, traditional (personal) communication.

Пандемия коронавируса кардинально изменила нашу жизнь, внедрившись во все сферы социума, затронув социальные отношения и взаимодействия, поменяв социальное поведение и коммуникации. Она породила новые способы и каналы общения, ранее непривычные для определенной части россиян. Возникает вопрос, перестали ли поддерживаться обычными способами семейные узы, дружеские связи, рабочие отношения в современном обществе. Какое место ТРАДИЦИОННОЕ (личное) общение занимает в жизни россиян в это нелегкое время? Найти ответы на эти вопросы, в определенной мере, 
позволяют результаты Инициативного всероссийского опроса «ВЦИОМСпутник».

Метод опроса — телефонное интервью.

Объем выборки: $\mathrm{n}=1600$ человек при доверительной вероятности 95\% и доверительном интервале $2,5 \%$.

Социально-демографическая характеристика респондентов

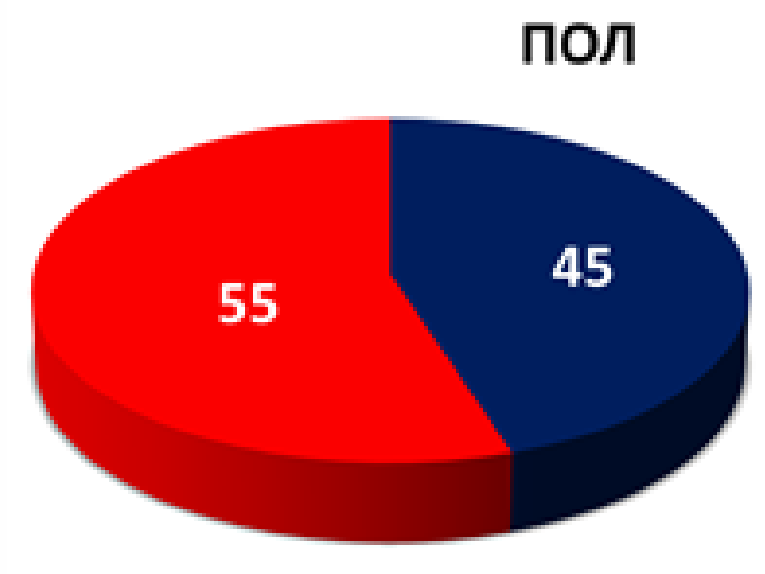

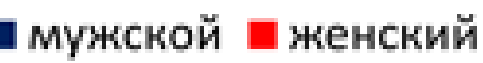

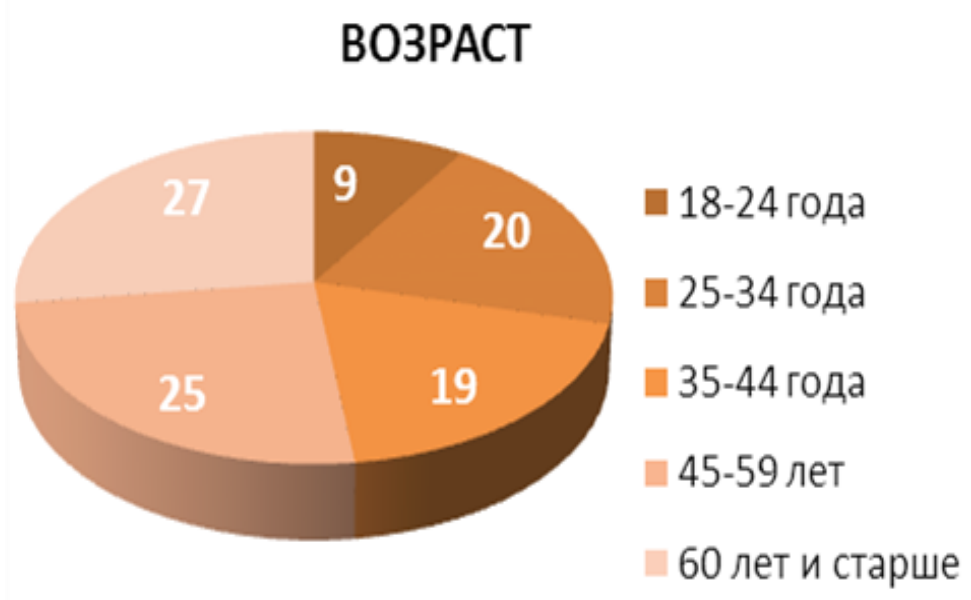




\section{ОБРАЗОВАНИЕ}

- Неполное среднее

образование

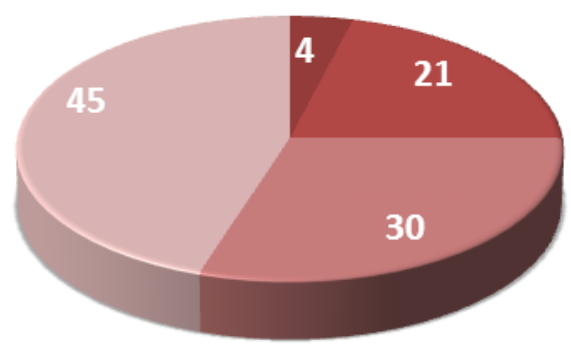

口 Среднее образование

(школа или Пту)

$\square$ Среднее специальное образование

(техникум)

$\square$ Незаконченное

высшее (с 3-го курса

вУЗа), высшее

образование

ТИП НАСЕЛЕННОГО ПУНКТА

Москва и Санкт-

Петербург

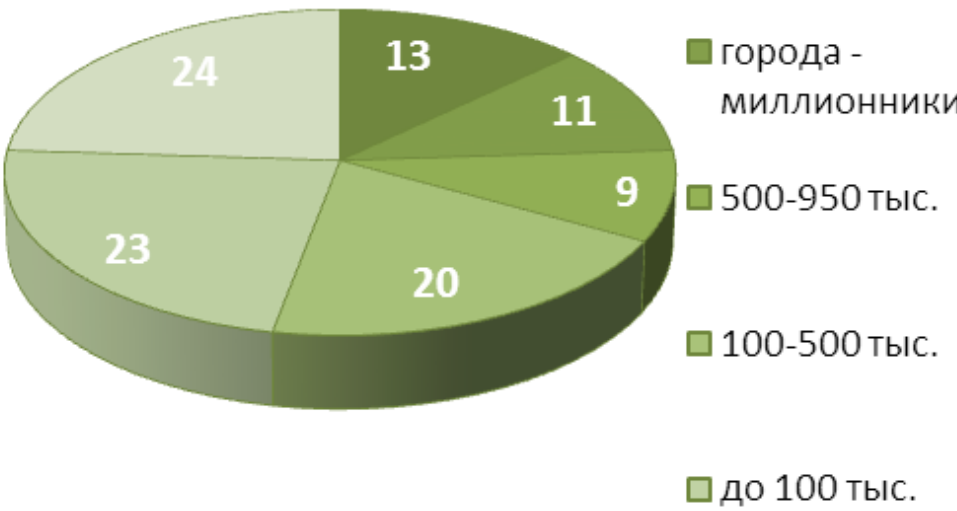

$\square$ село 
Традищионного общения (позиция «общался лично, находясь рядом с собеседником и не используя для этого электронные устройства») придерживаются почти половина респондентов (47\%). Это второй по значимости после мобильного телефона канал коммуникации. Причем, не отмечается каких-то особых гендерных различий, зато по возрастному критерию этот показатель снижается пропорционально повышению возраста респондентов (см. Рисунок 1).

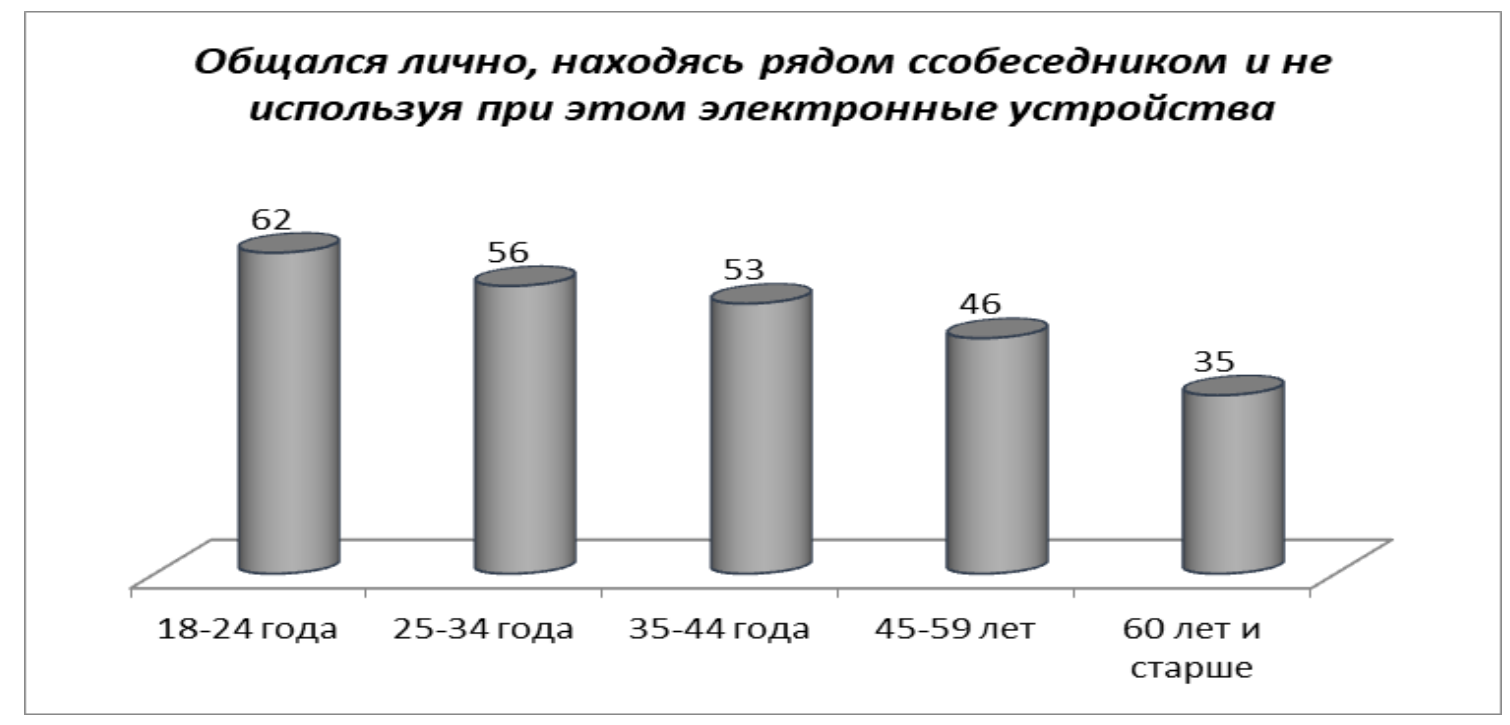

Рис. 1. Распределение ответов респондентов по возрастным группам на вопрос «Припомните, пожалуйста, какими способами Вы общались с близкими и знакомыми в последние 2-3 месяца?» - позиция «Общался лично, находясь рядом с собеседником и не используя для этого электронные устройства» $(\%)$

В качестве объяснения этой тенденции можно привести два аргумента:

- несоблюдение молодыми людьми тех рекомендаций и рамок, в которые поставила нас пандемия,

- режим самоизоляции людей старше 60 лет.

Территориальный аспект общения. Существует определенный стереотип, что в небольших населенных пунктах люди больше приближены друг к другу не только территориально, но и социально: близкое соседство, все друг друга знают, широкие родственные связи и т.д. Такое тесное взаимодействие, как правило, способствует и традиционному личному общению, которое, согласно этой логике, должно преобладать, в первую очередь, в сельских поселениях. Сравнительный анализ ответов респондентов-сельчан и городских жителей 
позволяет опровергнуть этот стереотип. В результате был получен обратный эффект: жители сельской местности лично общались с близкими и знакомыми в последние 2-3 месяца гораздо меньше, чем горожане (см. Рисунок 2).

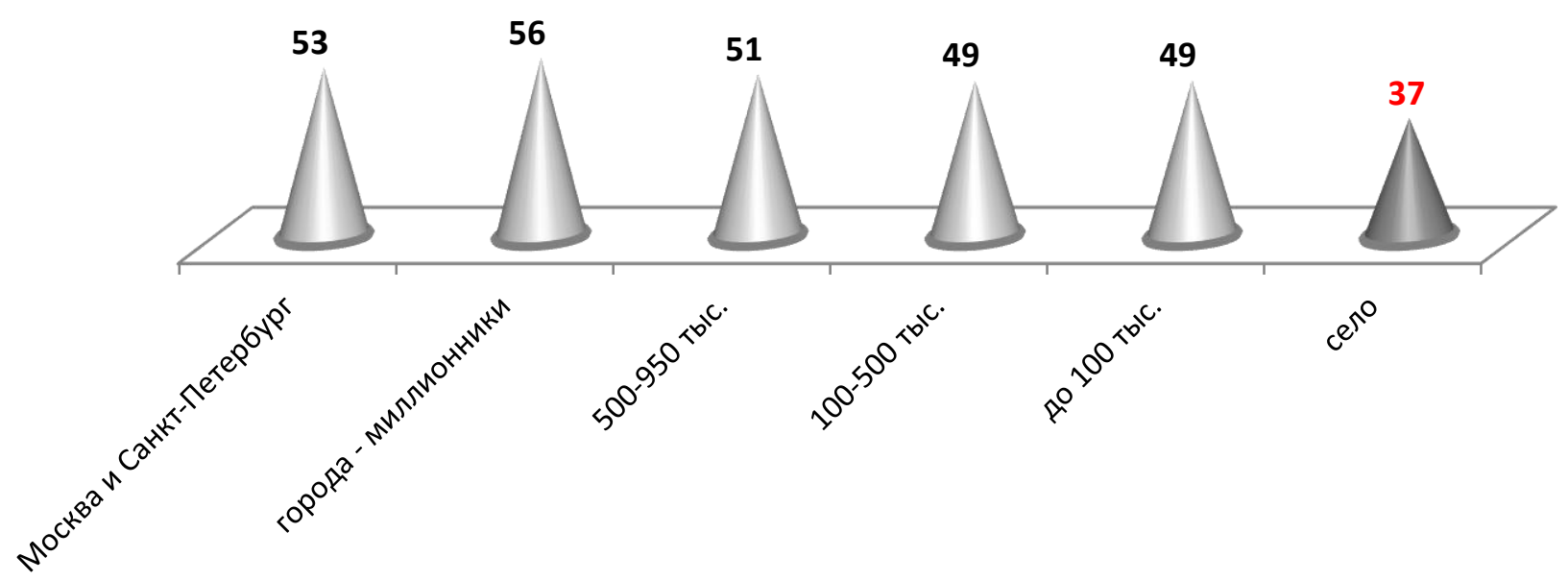

Рис. 2. Распределение ответов респондентов по территориальному признаку на вопрос «Скажите, пожалуйста, а каким образом Вы чаще всего общались с близкими и друзьями?» - позиция «Общался лично, находясь рядом с собеседником и не используя для этого электронные устройства» (\%)

Предположительно, данное распределение можно объяснить следующим образом:

- высокая коммуникабельность и интеграция городских жителей в большом, слабо контролируемом пространстве, способствующая нарушению короновирусных мер,

- ответственное принятие серьезных рисков пандемии сельскими жителями.

Аспект социального взаимодействия. Результаты опроса показали, что традиционным способом (лично) больше всего респонденты общаются с коллегами по работе (см. Рисунок 3). Это вполне объяснимо, так как определенные профессиональные вопросы зачастую необходимо решать только в личном контакте. 
На втором месте оказалось общение с близкими друзьями, которое можно объяснить тем, что в тяжелое время самоизоляции людям просто необходимо избавиться от состояния одиночества, тревожности, беспокойства. И ради этого некоторые нарушали дистанционный режим общения.

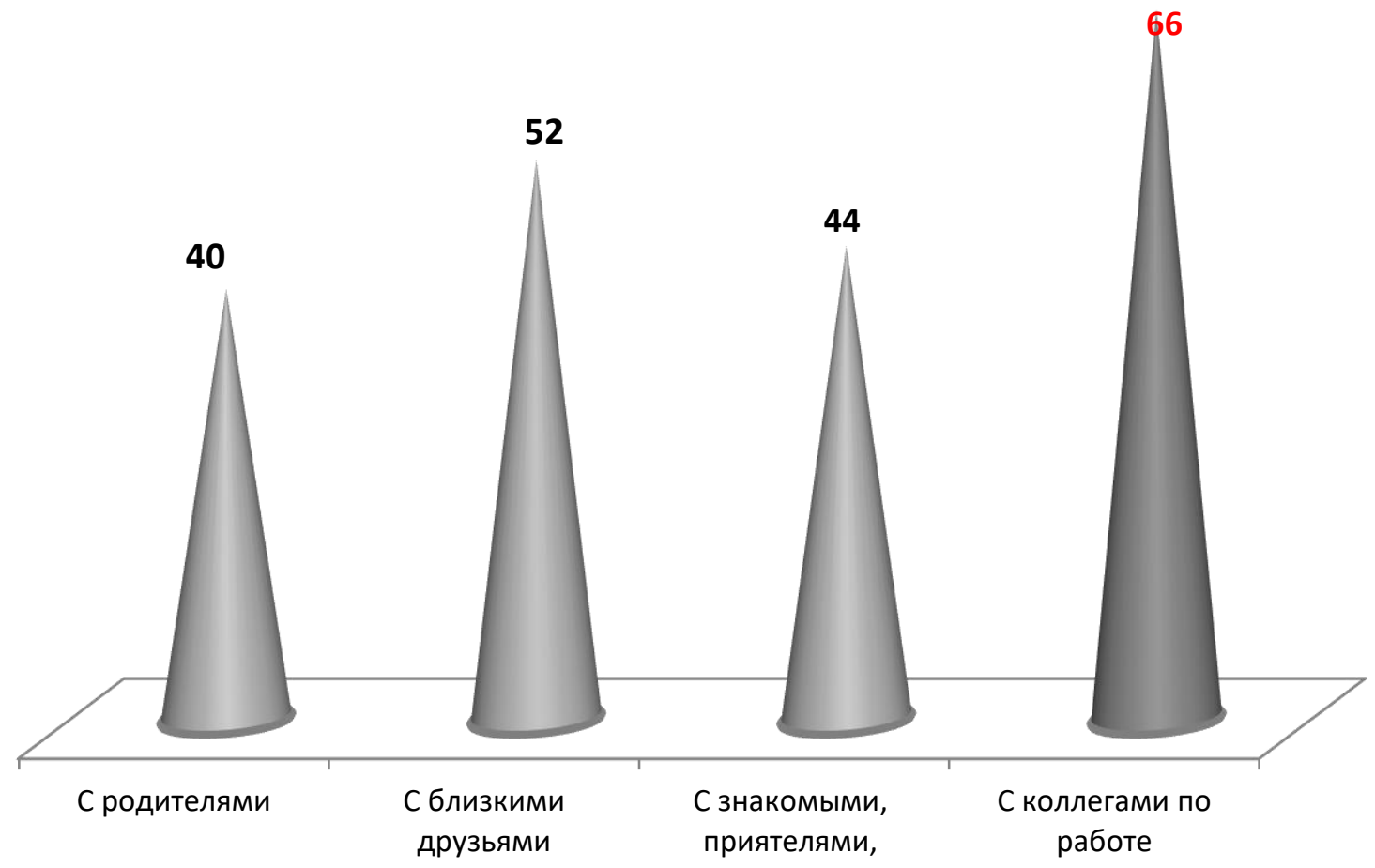

Рис. 3. Распределение ответов респондентов на вопрос «Скажите, пожалуйста, а каким образом Вы чаще всего общались с родителями, близкими друзьями, знакомыми и приятелями, коллегами по работе?» позиция «Общался лично, находясь рядом с собеседником и не используя для этого электронные устройства» (\%)

С родителями личное общение сохранилось у каждого четвертого респондента, причем, эти контакты преобладают в возрастных группах от 18 до 45 лет. Меньше всех общаются с родителями люди старше 60 лет, что можно объяснить спецификой этой возрастной группы: у ее представителей их уже может не быть (см. Рисунок 4). 


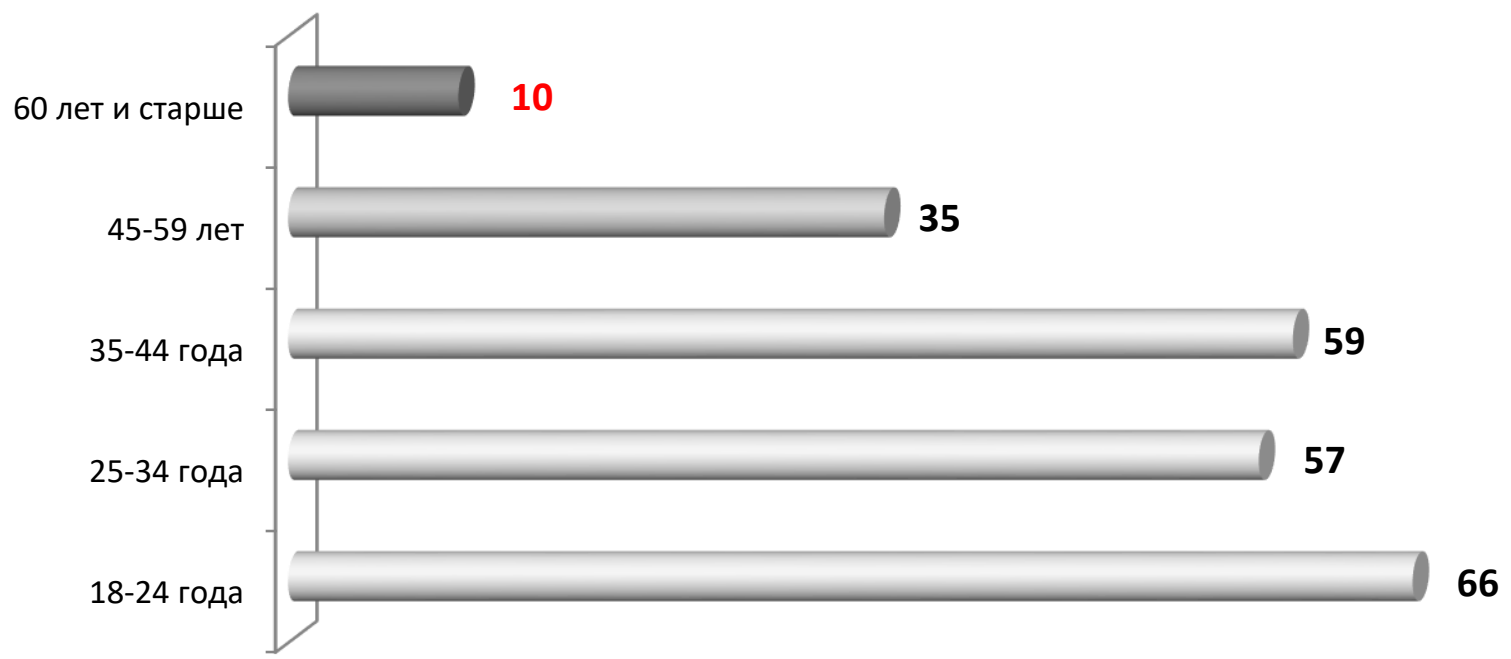

Рис. 4. Распределение ответов респондентов по возрасту на вопрос «Скажите, пожалуйста, а каким образом Вы чаще всего общаетесь с родителями» - позищия «Общался лично, находясь рядом с собеседником и не используя для этого электронные устройства» (\%)

Выводы. Традиционное (личное) общение, несмотря на ограничительные меры, связанные с пандемией, сохранилось в жизни россиян. Оно занимает третье место после общения по мобильному телефону и онлайн-переписки. Эта тенденция сохраняется во всех социально-демографических и территориальных группах. Традиционного вида общения придерживается почти половина всех опрошенных респондентов. Да, соблюдение антипандемийных мер научило нас улыбаться глазами, быть на дистанции друг от друга, поддерживать семейные узы альтернативными способами. Но хочется верить, что новая «культура короновируса» исчерпает себя в ближайшее время, и люди заживут привычным для себя способом: близко общаясь с родными и близкими, другими людьми, ведя активную жизнь в реальности, а не на просторах интернета. Пусть нынешняя пандемия не усилит стремление людей к автономному существованию, а наоборот простимулирует сокращение этих тенденций и замедлит данный процесс - процесс перехода общества на отдаленный режим жизни. 


\section{Список литературы}

1. Адамьянц Т.3. Социальные коммуникации : учебник для академического бакалавриата. - 2-е изд., перераб. и доп. - М. : Издательство Юрайт, 2018. - 200 с.

2. Волков Ю. Г., Курбатов В. И. Глобальная социология пандемии: отечественные и зарубежные сценарии и тренды послекоронавирусного мира // Гуманитарий Юга России. 2020. Том. 9. № 2. С. 17-32.

3. Горшков М.К. Пандемия очищает небосвод [Электронный ресурс] Режим доступа: https://lgz.ru/article/_17-18-6735-29-04-2020/pandemiyaochishchaet-nebosvod-/ - (дата обращения: 20.03.21)

4. Добров Е., Сысоев Т. 15 образов мира после короновируса [Электронный ресурс] - Режим доступа: http://www.sib-science.info/ru/news/15obrazov-mira-posle-koronav-06042020 - (дата обращения: 22.03.21)

5. Инициативный всероссийский опрос ВЦИОМ-Спутник (28 января 2021) [Электронный pecypc] - Режим доступа: https://old.wciom.ru/ index.php?id=236\&uid=10693 - (дата обращения: 27.02.21)

() А.П. Ушакова, 2021 